\title{
SOME IDEAS ON THE 50-MOVE RULE
}

\begin{abstract}
B.M. Kazîú
Almost on the eve of the FIDE's Rules Commission meeting in Seville, Spain on November 22-23, 1987, B.M. Kažić wrote to us in his capacity of Chairman of this Commission. We are happy with Mr Kažic's communication, not in the least because it promises to build a step towards a bridge between computerderived chess knowledge and those in charge of FIDE's Rules. The Editor-in-Chief's letter to which Mr Kažić responds proposed a uniform value of $k$ for a $k$-move rule ( $k$ to be set by FIDE, but presumably to be $>$ 50). We refer to Dekker et al. (1988) in a special issue of Artificial Intelligence (Eds. H.J. Berliner and D.F. Beal).
\end{abstract}

We quote the essence of Kažić's letter in full, asking our readers to keep in mind that this is one Commission member's opinion, formulated before the Commission's last meeting and therefore not binding.

"After I have received your material I have asked the Secretariat of FIDE to send it to all members of the Rules Commission. As you may know, our Commission has two meetings in Sevilla on 22 and 23 of November. We have on agenda a discussion regarding Article 10.8 and 10.9 of the Laws of Chess.

There are very different opinions. The Grandmaster Association has proposed different exceptions or, better to say, diversification of extensions of the 50-move rule. They suggest 75 moves for [KQP(a)KQ and $\mathrm{KQP}(\mathrm{h}) \mathrm{KQ}$ ], 65 moves for [KQP(b)KQ and $\mathrm{KQP}(\mathrm{g}) \mathrm{KQ}$ ], then 55 moves for [KQP(c)KQ and $\mathrm{KQP}(\mathrm{f}) \mathrm{KQ}]$ and 65 moves for [KQP(d)KQ and $\mathrm{KQP}(\mathrm{e}) \mathrm{KQ}]$.

I am afraid this will be too complicated for arbiters and organisers. But there is one other question: a player must play like a computer in order to win in the prescribed number of moves. But if he plays [the KQK endgame] then he has not to play like a machine, he can make many mistakes and yet comfortably win within 50 moves.

In the USSR they keep the rule: 50 moves without exceptions. Maybe this is a solution, but many players, when they get an exceptional ending, will not be happy to remain without possibility to play for a win.

I do not like to change the Laws too often, so we must study the question very seriously. I hope you shall offer us your help in the future too. Thank you in advance."

\section{COMPUTERS AT THE AMERICAN OPEN TOURNAMENT}

\section{Stuart Cracraft}

Finally, we paraphrase rather than extract the information received from Stuart Cracraft. The American Open Chess Championship (Dallas, Texas) over the Thanksgiving weekend 1987 showed large areas of doubt in the specifications of the main computer entrants.

Perhaps the requirements were over-exigent: not only would a certification have to precede an entry, the certification would, by the tournament rules, have to refer to precisely the software actually employed which, moreover, was also stipulated to need to be commercially available. The details of the eight-round tourney are freely available from S. Cracraft, Dep. of Mathematics, UCLA, Los Angeles, California 90024, USA, and will not be set out here.

The best that can be said is that the computer programs, one and all were soundly trounced by their human opponents. In the end 28 points went to Fidelity, 26 points to Mephisto and 24 to Novag, all out of 48 games.

More important than that, the gossip over-rife in such tourneys was almost unanimous, so our Commercials are hell-bent on producing a master-rated program within one year. It is easy to imagine its impact and hard to know at what level to peg its price. 